\title{
Analysis of Chloramphenicol in Drinking Water Using an Evaporation Preparative Step and Isotope Dilution Liquid Chromatography-Tandem Mass Spectrometry
}

\author{
Yonggang Li ${ }^{1}$, Xiaohong Liu ${ }^{1}$, Rui Zhang ${ }^{1}$, DerGer ZomPa ${ }^{2}$, Ping Luo ${ }^{1}$, Lin Tang ${ }^{1}$, \\ Xiao Liu ${ }^{1}$, Yan Zhou ${ }^{1}$ and Sheng Wen ${ }^{1 *}$ \\ ${ }^{1}$ Hubei Provincial Key Laboratory for Applied Toxicology, Hubei Provincial Centre for Disease Control and Prevention, \\ Wuhan, 430079, China \\ ${ }^{2}$ Shannan region Centre for Disease Control and Prevention, Shannan region of Tibet, 856000, China
}

Accepted: 30 September 2015

\begin{abstract}
A reliable isotope dilution method for the determination of chloramphenicol (CAP) in drinking water was developed by using an evaporation preparative step. Each sample was monitored by ultrahigh-pressure liquid chromatography (UHPLC) coupled to tandem mass spectrometry (MS/MS) using an electrospray ionization interface (ESI) in negative ion modes. Recoveries of spiked samples were in the range from $93.2 \%$ to $95.7 \%$ with intra-day relative standard deviation lower than $6.7 \%$ and inter-day relative standard deviation lower than $8.2 \%$. Limit of quantification (LOD) was $0.002 \mathrm{ng} / \mathrm{mL}$. The developed method was successfully applied to the analysis of CAP in drinking water of Shannan region of Tibet.
\end{abstract}

Keywords: UHPLC-MS/MS, chloramphenicol, evaporation, isotope dilution, drinking water

\section{Introduction}

Chloramphenicol (CAP) (structure shown in Figure 1) is widely used in animal husbandry on a large scale to control diseases or as growth promoters in China [1]. CAP is cheap and easy to prepare, and it exhibits effective antibacterial activity against a wide variety of Gram-positive and Gram-negative bacteria $[2,3]$. CAP may directly expose to the environment by leaching from uneaten feeds or from the animals' excrement and also directly enter the environment through pharmaceutical wastewater, which might cause potential risk on consumer health [4-6]. Although the Chinese government [7], as well as European Union [8] or United States of America (EPA 822R-06-013), has taken no legislation and concentration limit of CAP in drinking water, in order to minimize the risk and ensure food safety, a simple and reliable analytical method needs to be developed and validated.

Many methods have been published for the detection and quantification of CAP from environmental and food samples. The enzyme-linked immunosorbent assay (ELISA) [2, 9], thin piezoelectric immunosensor [10], surface plasmon resonance (SPR) [11], molecularly imprinted polymer (MIP) [12], gas chromatography (GC) [13], GC-mass spectrometry (MS) [14], and liquid chromatography (LC) [15-17] achieved good results. In the recent years, high-performance liquid chromatography (HPLC) coupled to mass spectrometry (MS) [18, 19], or coupled to tandem mass spectrometry (MS/MS) [6, 18, 20-23], had become the best choice for the determination of CAP because of its advantages of high selectivity and sensitivity, timesaving, and the accuracy of quantification and confirmation.

Liquid-liquid extraction (LLE) [21], solid-phase microextraction (SPME) cartridges [24], molecular imprinted polymers (MIPs) [14], and solid-phase extraction (SPE) [17] were mainly applied to extract CAP in many reported methods, but which are expensive and time-consuming. Thus, it is necessary to develop

* Author for correspondence: wenshenggy@aliyun.com<smiles>O=C(NC(CO)C(O)c1ccc([N+](=O)[O-])cc1)C(Cl)Cl</smiles>

Figure 1. Chemical structures of CAP

generic procedures to make fast, cost-effective, and accurate detection possible. Fortunately, an evaporation preparative step has been used as a valuable way to detect acrylamide in water [25], but not used in the detection of CAP.

In this study, an evaporation preparative step method with isotope dilution UHPLC-MS/MS has been developed for the determination of CAP in drinking water from Shannan region of Tibet. The developed method meets the detection requirements, due to the effectiveness of the extraction procedure and the fast chromatographic analysis.

\section{Experimental}

Materials and reagents. Standards for CAP and $\mathrm{d}_{5}$-CAP were obtained from Dr. Ehrenstorfer (Augsburg, Germany). HPLC-grade acetonitrile was obtained from TEDIA (Ohio State, USA). Water was purified using a Milli-Q purification system (resistivity, 18.2 M 2 , Millipore, Bedford, MA, USA). Miniuniprep G2 Syringeless Filters $(0.2 \mu \mathrm{m}$ PTFE) were obtained from Whatman (Buckinghamshine, UK).

Stock standard solutions were prepared in acetonitrile by exact weighing of the compounds and stored at $-20^{\circ} \mathrm{C}$. Working standard solution was prepared by diluting stock solutions with acetonitrile and stored at $4{ }^{\circ} \mathrm{C}$.

Sample collection. Ten drinking water samples from Shannan region of Tibet were collected in glass bottles and stored in the dark below $4{ }^{\circ} \mathrm{C}$.

This is an open-access article distributed under the terms of the Creative Commons Attribution-NonCommercial 4.0 International License (https://creativecommons.org/licenses/by-nc/4.0/), which permits unrestricted use, distribution, and reproduction in any medium for non-commercial purposes, provided the original author and source are credited, a link to the CC License is provided, and changes - if any - are indicated. 
Instruments and apparatus. LC analysis was performed in an Agilent 1200SL Series Rapid Resolution LC System (CA, USA) equipped with a binary pump, degasser, autosampler, and column heater. An SB-Aq C18 column $(100 \mathrm{~mm} \times 3.0 \mathrm{~mm}$, $1.8 \mu \mathrm{m}$ particle size) from Agilent was used for chromatographic separation. MS/MS detection was performed using an Agilent 6460 Triple Quadrupole LC/MS (QQQ) equipped with an ESI source. Rotary evaporator (Flawil, Switzerland), model R-210, was obtained from Büchi. Vortex mixer, model HQ-60, was obtained from Beijing North TZBiotechnology Development Corp. Ltd. (Beijing, China).

Chromatographic conditions. The mobile phase was consisted of acetonitrile (eluent A) and water (eluent B). The portion of eluent A was $50 \%$ and keeping constant for $5 \mathrm{~min}$. The flow rate was set at $0.3 \mathrm{~mL} / \mathrm{min}$, and column temperature was kept at $40^{\circ} \mathrm{C}$. The injection volume was $10 \mu \mathrm{L}$.

MS/MS conditions. The mass spectrometer was connected to the UHPLC system via an electrospray ionization (ESI) interface in negative mode. Source parameters were as follows: capillary voltage at $3.5 \mathrm{kV}$, sheath gas temperature at $320^{\circ} \mathrm{C}$, sheath gas flow rates at $11 \mathrm{~L} / \mathrm{min}$, gas temperature at $345^{\circ} \mathrm{C}$, gas flow at $6 \mathrm{~L} / \mathrm{min}$, nebulizer pressure at $45 \mathrm{psi}$, and nozzle voltage at $500 \mathrm{~V}$.

The multiple reaction monitoring mode (MRM) was applied for quantification. The parameters of transitions and the applied fragment or voltages and collision energy of are shown in Table 1.

Sample preparation. Volumes of $50 \mathrm{~mL}$ of water were transferred to a $250 \mathrm{~mL}$ boiling flask. After spiking with $5 \mathrm{ng}$ of internal standard, $\mathrm{d}_{5}-\mathrm{CAP}$, the sample was evaporated with a rotary evaporator under vacuum of $250 \mathrm{mbar}$ at a temperature of $65{ }^{\circ} \mathrm{C}$ until the boiling flask was dry. After that, $1 \mathrm{~mL}$ acetonitrile was added and vortexed for $1 \mathrm{~min}$. Then, $0.5 \mathrm{~mL}$ of supernatant was added into Mini-uniprep G2 Syringeless Filters. Each sample was injected into the UHPLC-MS/MS system for analysis.

Method validation. Linearity, accuracy, precision, limit of detection (LOD), and limit of quantification (LOQ) were applied for evaluating the applicability of optimized method. Matrix effects were investigated by comparing responses obtained for the standard in blank extract solution and in pure solvent at a concentration of $5 \mathrm{ng} / \mathrm{mL}$. Linearity was evaluated using isotope dilution calibration in solvent with CAP concentrations corresponding to $0.2,1,5,10$, and $20 \mathrm{ng} / \mathrm{mL}$ and containing a fixed amount of $\mathrm{d}_{5}$-CAP $(5 \mathrm{ng} / \mathrm{mL})$. Trueness and precision (intra-day and inter-day) were studied by spiking blank water at three fortification levels which are shown in Table 2 by analyzing six replicates at each concentration. Inter-day precision was evaluated by analyzing six spiked samples on three separate days in $0.05 \mathrm{ng} / \mathrm{mL}$. Limits of quantification (LOQs) and limits

Table 1. Retention time windows (REWs) and MS/MS parameters of $\mathrm{CAP}$ and $\mathrm{d}_{5}-\mathrm{CAP}$

\begin{tabular}{lcccc}
\hline Compound & $\begin{array}{c}\text { RTW } \\
(\mathrm{min})\end{array}$ & $\begin{array}{c}\text { Frag voltage } \\
(\mathrm{V})\end{array}$ & $\begin{array}{c}\text { Quantitation } \\
\text { transition* }\end{array}$ & $\begin{array}{c}\text { Confirmation } \\
\text { transition* }\end{array}$ \\
\hline CAP & 2.2 & 138 & $321>257.1(5)$ & $321>152.1(9)$ \\
d5-CAP & 2.2 & 150 & $326>262.1(5)$ & $326>157.1(9)$
\end{tabular}

*Collision energy $(\mathrm{eV})$ is given in brackets.

Table 2. Validation parameters of the developed method $(n=6)$

\begin{tabular}{lccccc}
\hline Compound & $\begin{array}{c}\text { Spiked } \\
\text { level } \\
(\mathrm{ng} / \mathrm{mL})\end{array}$ & $\begin{array}{c}\text { Recoveries }^{a} \\
(\%)\end{array}$ & $\begin{array}{c}\text { Inter-day } \\
\text { precision } \\
(\%)\end{array}$ & $\begin{array}{c}\mathrm{LOD} \\
(\mathrm{ng} / \mathrm{mL})\end{array}$ & $\begin{array}{c}\mathrm{LOQ} \\
(\mathrm{ng} / \mathrm{mL})\end{array}$ \\
\hline CAP & 0.01 & $95.7(8.1)$ & 8.4 & 0.002 & 0.007 \\
& 0.05 & $93.2(6.7)$ & & & \\
& 0.1 & $94.2(4.5)$ & & &
\end{tabular}

${ }^{a}$ Innerday precision are given in bracket $(n=6)$. of detection (LODs) were determined as the amount of analyte for which signal-to-noise ratios $(\mathrm{S} / \mathrm{N})$ were equal than 10 and 3 , respectively.

\section{Results and discussion}

Optimization of UHPLC-MS/MS conditions. Recently, LC or UHPLC coupled to MS/MS is the most suitable technique for detection of CAP because it allowed the robust analysis of the analytes at low levels in complexs [15, 26, 27]. In order to obtain nice peak shape and resolution, $\mathrm{C}_{18}$ column was used in most reports $[20,28,29]$. In addition, the experiments had evaluated the mobile phases consisting of ACN and water which provided good sensitivity and resolution. The retention time was $2.2 \mathrm{~min}$, and the toal run time was $5 \mathrm{~min}$.

To optimize the mass spectrometric conditions, $1 \mu \mathrm{g} / \mathrm{mL}$ standard solution of CAP and $\mathrm{d}_{5}$-CAP was injected into MS/MS. Precursor ion, product ion, fragmentor, and collision energy were evaluated by Masshunter Optimizer (B.03.01) in ESI negative mode. Under these conditions, protonated molecules $[\mathrm{M}-\mathrm{H}]^{-}$ were detected as the precursor ion for CAP. The MS/MS parameters are shown in Table 1.

Sample preparation optimization. In some reported methods, LLE [21], SPME [24], MIP [14], and SPE [17] were mainly used to extract CAP. However, they are timeconsuming and expensive. In our study, an evaporation preparative step was employed to enrich analyte. To achieve the highest recoveries, different combinations of vacuum degree and temperature were evaluated. These combinations included the following: $\left(250 \mathrm{mbar}+55^{\circ} \mathrm{C}\right),(250 \mathrm{mbar}+$ $\left.60{ }^{\circ} \mathrm{C}\right),\left(250 \mathrm{mbar}+65^{\circ} \mathrm{C}\right)$, and $\left(300 \mathrm{mbar}+60{ }^{\circ} \mathrm{C}\right)$. Only one spiked concentration of $0.05 \mathrm{ng} / \mathrm{mL}$ was evaluated during this procedure. Figure 2 shows the impact on time and recoveries. We choose $\left(250 \mathrm{mbar}+65^{\circ} \mathrm{C}\right)$ as optimized method for the shortest time (12 $\mathrm{min}$ ) and acceptable recovery (93.2\%).

Matrix effects. The presence of matrix components can affect the ionization efficiency of analytes, leading to either suppression or enhancement of the signal. Matrix effects were investigated by comparing responses obtained for the standard in blank extract solution and in pure solvent at a concentration of $5 \mathrm{ng} / \mathrm{mL}$ [30]. In addition, the peak area of quantitation transition $(321>257.1)$ was 3100 and 15906 which were shown in Figure 3, so strong significant matrix suppression effects were observed. In our study, isotope dilution techniques provide the benefit of compensating biases caused by ion suppression by co-eluting matrix interferences [31].

\section{Validation}

Linearity. Calibration curve was constructed with concentration sequences of $0.2,1,5,100$, and $20 \mathrm{ng} / \mathrm{mL}$ and containing a fixed amount of $\mathrm{d}_{5}$-CAP $(5 \mathrm{ng} / \mathrm{mL})$. The linear equation was $y=1.105 x+0.031\left(R^{2}=0.999\right)$, which demonstrates that the method can be used to monitor the CAP residues reliably.

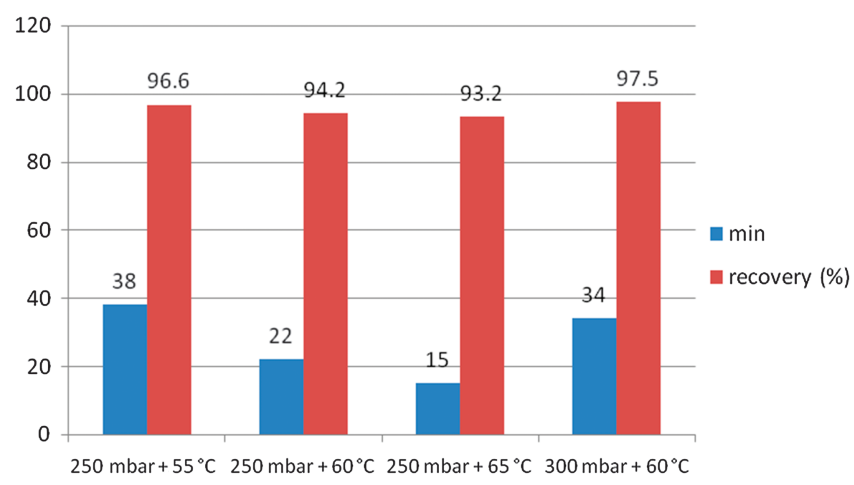

Figure 2. Effects on recoveries and time of different condition 
Signal response

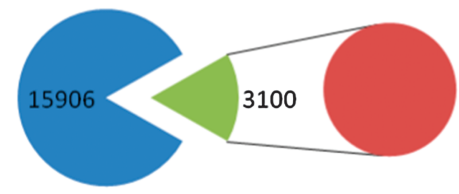

w standard solution in pure solvent

standard solution in matrix

Figure 3. Matrix effects on LC-MS/MS signals

Trueness and precision. Recoveries, intra-day precision, and inter-day precision for CAP were performed by adding standard to analyte-free water samples at low, intermediate, and high concentration levels. Mean recoveries and coefficients of variation of CAP were shown in Table 2. The RSDs of the intra-day precision were in the range $4.5 \%$ to $8.1 \%$, while the RSDs of inter-day precision were less than $8.4 \%$. Figure 4 shows the MRM chromatograms of blank samples
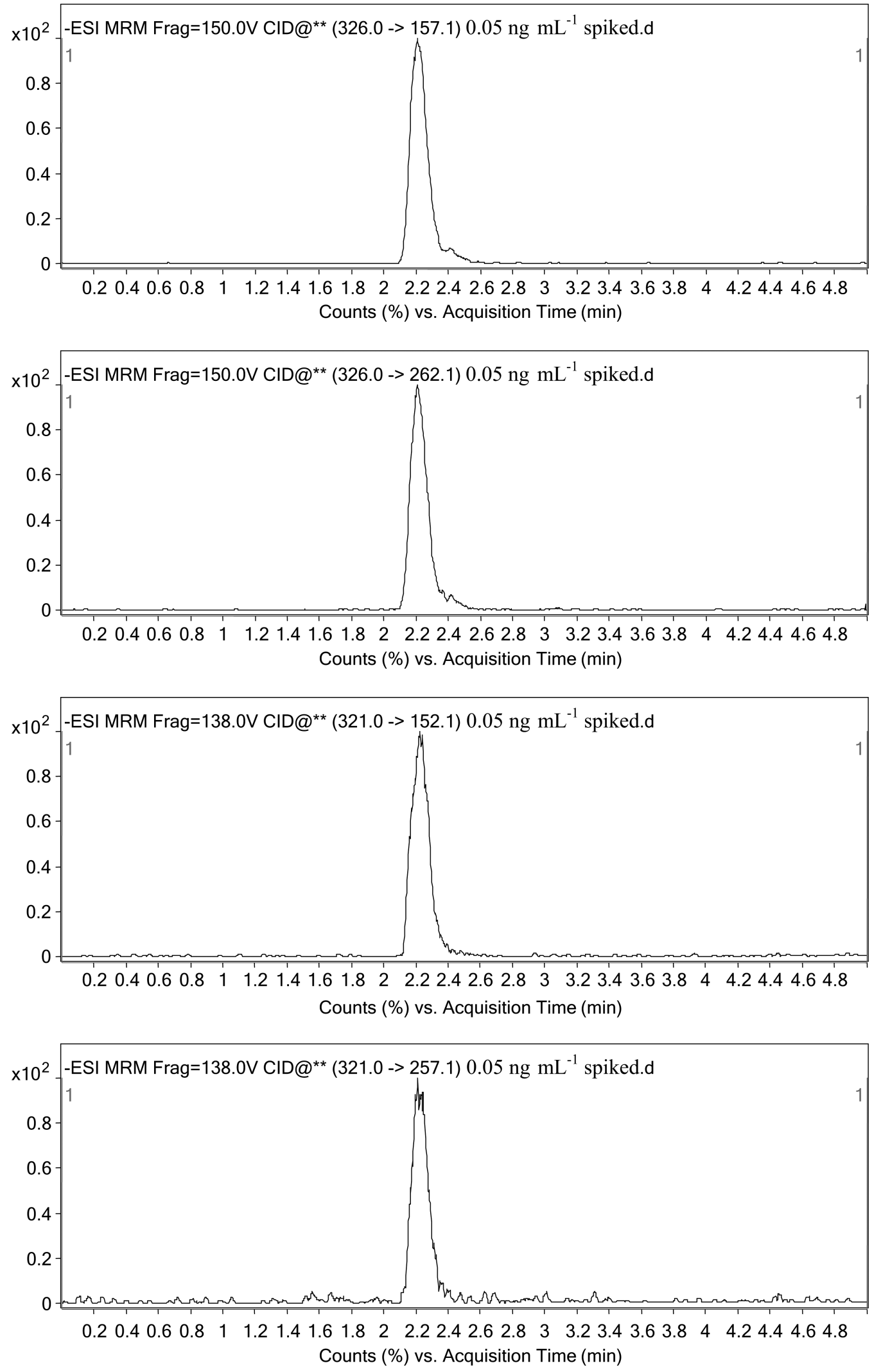

Figure 4. MRM chromatograms of samples spiked with CAP in $0.05 \mathrm{ng} / \mathrm{mL}$ 
fortified with target analyte. All these data revealed that the established method had an acceptable result according to EU SANCO/12571/2013 guidance document [32].

Limit of detection and limit of quantification. The detection (quantitation) limit was determined by successive analyses of chromatographic extracts of water spiked samples with decreasing amounts of CAP standard until a signal-to-noise ratio of 3:1 (10:1) was reached. The LOD and LOQ of each analyte are shown in Table 2.

Application to real samples. The develop method was applied to 10 water samples collected in Shannan region of Tibet. The result indicated that the method we set up was suitable for the detection of analytes, and all the samples analyzed in this study were lower than the LOD.

\section{Conclusions}

A new method based on an evaporation preparative step coupled with isotope dilution UHPLC-MS/MS has been developed for the determination of CAP in drinking water in Shannan region of Tibet. This developed method exhibits good validation parameters in terms of linearity, trueness, precision, and LOQ for CAP detection. This method is simple, fast, and high throughput and could be applied for regular monitoring of CAP in water by routine.

Acknowledgments. We appreciate the Shannan CDC employee for their help in the sampling. This research was supported by the science project of Hubei Provincial Centre for Disease Control and Prevention (Y2013W07 and Y2013W01).

\section{References}

1. Yuan, M.; Sheng, W.; Zhang, Y.; Wang, J.; Yang, Y.; Zhang, S.; Goryacheva, I. Y.; Wang, S. Anal. Chim. Acta. 2012, 751, 128.

2. Mbodi, F. E.; Nguku, P.; Okolocha, E.; Kabir, J. Food Addit. Contam., Part A 2014, 31, 1834.
3. Nicolich, R. S.; Werneck-Barroso, E.; Marques, M. A. S. Anal. Chim. Acta. 2006, 565, 97.

4. Rocha Siqueira, S. R.; Luiz Donato, J.; de Nucci, G.; Reyes, F. G. J. Sep. Sci. 2009, 32, 4012.

5. Karaseva, N. A.; Ermolaeva, T. N. Talanta 2012, 93, 44.

6. Kaufmann, A.; Butcher, P.; Maden, K.; Walker, S.;Widmer, M. Anal. Chim. Acta. 2015, $862 c, 41$.

7. China, M. GB5749-2006 2006.

8. Schets, F.; Nobel, P.; Strating, S.; Mooijman, K.; Engels, G.; Brouwer, A. Lett. Appl. Microbiol. 2002, 34, 227.

9. Scortichini, G.; Annunziata, L.; Haouet, M. N.; Benedetti, F.; Krusteva, I.; Galarini, R. Anal. Chim. Acta 2005, 535, 43.

10. Karaseva, N.; Ermolaeva, T. Talanta 2012, 93, 44

11. Ashwin, H. M.; Stead, S. L.; Taylor, J. C.; Startin, J. R.; Richmond, S. F.; Homer, V.; Bigwood, T.; Sharman, M. Anal. Chim. Acta 2005, 529, 103.

12. Boyd, B.; Björk, H.; Billing, J.; Shimelis, O.; Axelsson, S.; Leonora, M.; Yilmaz, E. J. Chromatogr. A 2007, 1174, 63.

13. Akhtar, M. H.; Danis, C.; Sauve, A.; Barry, C. J. Chromatogr. A 1995 , 696, 123.

14. Rejtharová, M.; Rejthar, L. J. Chromatogr. A 2009, 1216, 8246.

15. Han, J.; Wang, Y.; Yu, C.; Li, C.; Yan, Y.; Liu, Y.; Wang, L. Anal. Chim. Acta. 2011, 685, 138 .

16. Wang, L.; Yang, H.; Zhang, C.; Mo, Y.; Lu, X. Anal. Chim. Acta 2008, 619, 54.

17. Liu, S.; Wu, X. Z.; Gao, Z. H.; Jiao, F. Analytical Methods 2013, 5, 1150.

18. Huang, J.-F.; Zhang, H.-J.; Feng, Y.-Q. J. Agric. Food Chem. 2006, 54, 9279

19. Hormazábal, V.;Yndestad, M. J. Liq. Chromatogr. Relat. Technol. 2001, $24,2477$.

20. Kawano, S.-i.; Hao, H.-Y.; Hashi, Y.; Lin, J.-M. Chinese Chemical Letters 2015.

21. Lu, X. W.; Dang, Z.; Yang, C. Int. J. Environ. Sci. Technol. 2009, 6, 597.

22. Rocha Siqueira, S. R.; Luiz Donato, J.; de Nucci, G.; Reyes, F. G. R. J. Sep. Sci. 2009, 32, 4012.

23. Rønning, H. T.; Einarsen, K.; Asp, T. N. J. Chromatogr. A 2006, 1118, 226.

24. Aresta, A.; Bianchi, D.; Calvano, C. D.; Zambonin, Cg. J. Pharm. Biomed. Anal. 2010, 53, 440 .

25. Chu, S.; Metcalfe, C. D.; Chem, A. Anal. Chem. 2007, 79, 5093.

26. Xia, X.; Wang, Y.; Wang, X.; Li, Y.; Zhong, F.; Li, X.; Huang, Y.; Ding, S.; Shen, J. J. Chromatogr. A 2013, 1292, 96.

27. Cronly, M.; Behan, P.; Foley, B.; Malone, E.; Martin, S.; Doyle, M.; Regan, L. Food Addit Contam Part A Chem Anal Control Expo Risk Assess 2010, $27,1233$.

28. Tajik, H.; Malekinejad, H.; Razavi-Rouhani, S. M.; Pajouhi, M. R.; Mahmoudi, R.; Haghnazari, A. Food Chem. Toxicol. 2010, 48, 2464.

29. Forti, A. F.; Campana, G.; Simonella, A.; Multari, M.; Scortichini, G. Anal. Chim. Acta 2005, 529, 257.

30. Hou, X.; Li, Y.; Cao, S.; Zhang, Z.; Wu, Y. Chromatographia 2010, 71, 135.

31. Lee, S.; Kim, B.; Kim, J. J. Chromatogr. A 2013, 1277, 35.

32. Cervera, M.; Portolés, T.; López, F.; Beltrán, J.; Hernández, F. Anal Bioanal. Chem. 2014, 406, 6843. 